\title{
Association of sedentary behavior with overweight and abdominal obesity in older adults
}

\author{
Associação entre comportamento sedentário com o excesso de peso e obesidade \\ abdominal em idosos
}

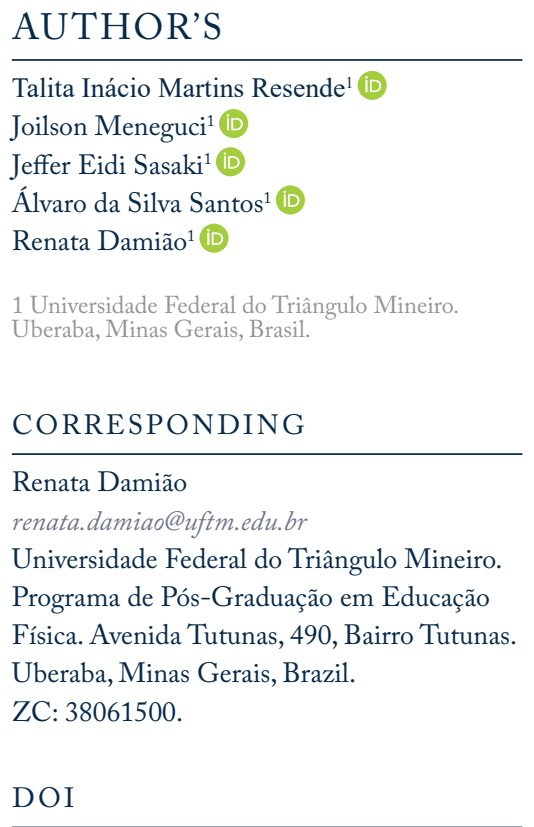

$10.12820 /$ rbafs. $24 \mathrm{e} 0074$
Keywords: Sedentary lifestyle; Body mass index; Waist circumference; Cross-sectional study.

RESUMO

O objetivo deste estudo foi examinar a associação entre o comportamento sedentário e o excesso de peso e a obesidade abdominal em idosos. Trata-se de um estudo transversal com idosos de ambos os sexos, residentes nos municípios da Superintendência Regional de Saúde de Uberaba, Minas Gerais. O comportamento sedentário foi avaliado pelo tempo despendido sentado em um dia de semana e um dia de final de semana. A massa corporal, estatura e circunferência da cintura foram aferidas. $O$ excesso de peso foi determinado por meio do indice de massa corporal e a obesidade abdominal pela e circunferência da cintura. Na estatística, empregou-se análises de regressão de Poisson com variância robusta. Participaram do estudo 3.223 idosos, com média de idade de 70 \pm 7,26 anos, sendo 61,3\% mulheres. Quando realizadas análises ajustadas pelas variáveis sociodemográficas, percep̧̧ão de saúde e comportamentais, não foram verificadas associações entre os quartis de comportamento sedentário com o excesso de peso ( $2^{\circ}$ quartil: $R P=0,99 ; 1 C 95 \%: 0,94-1,05 ; 3^{\circ}$ quartil: $R P=0$,99; IC95\%: 0,93-1,07; $4^{\circ}$ quartil: $R P=1,07 ;$ IC95\%: 1,00-1,13) e obesidade abdominal $\left(2^{\circ}\right.$ quartil: $R P=1,04 ;$ IC95\%: 1,00-1,08; $3^{\circ}$ quartil: $R P=1,03 ;$ IC95\%: 0,98-1,08; $4^{\circ}$ quartil: $R P=$ 0,98; IC95\%: 0,94-1,03). O comportamento sedentário não associou com o excesso de peso e com a obesidade abdominal em idosos.

Palavras-chave: Estilo de vida sedentário; Índice de massa corporal; Circunferência da cintura; Estudo transversal.

\begin{abstract}

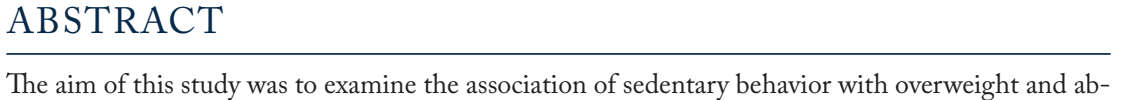
dominal obesity in older adults. This was a cross-sectional study with older men and women residing in the municipalities of the Regional Health Superintendency of Uberaba, Minas Gerais. Sedentary behavior was assessed according to the time spent sitting on a weekday and a weekend day. Body mass, height and waist circumference were measured. Excess weight was determined by means of body mass index, while abdominal obesity by waist circumference. Poisson regression analyzis with robust variance were used to examine the association of sedentary behavior with overweight and abdominal obesity. The total sample consisted of 3223 older people $(61.3 \%$ women), with a mean age of $70 \pm 7.26$ years. There was no association between quartiles of sedentary behavior and overweight $\left(2^{\text {nd }}\right.$ quartile: $\mathrm{PR}=0.99 ; 95 \% \mathrm{CI}: 0.94-1.05 ; 3^{\text {rd }}$ quartile: $\mathrm{PR}=0.99 ; 95 \% \mathrm{CI}: 0.93-1.07 ; 4^{\text {th }}$ quartile: $\mathrm{PR}=1.07 ; 95 \% \mathrm{CI}: 1.00-1.13)$ and abdominal obesity $\left(2^{\text {nd }}\right.$ quartile: $\mathrm{PR}=1.04 ; 95 \% \mathrm{CI}: 1.00-1.08$; $3^{\text {rd }}$ quartile: $\mathrm{PR}=1.03 ; 95 \% \mathrm{CI}: 0.98-1.08 ; 4^{\text {th }}$ quartile: $\left.\mathrm{PR}=0.98 ; 95 \% \mathrm{CI}: 0.94-1.03\right)$ when analyses were adjusted for sociodemographic, health perception and behavioral variables. The sedentary behavior was not associated with overweight and abdominal obesity in the elderly.
\end{abstract}

This work is licensed under the Creative Commons Attribution-NonCommercial-ShareAlike 4.0 International License.

\section{Introduction}

Evidence suggests that older adults spend about $60 \%$ to $70 \%$ of their waking hours in sedentary behavior ${ }^{1}$. Recent studies highlighted that sedentary behavior is associated with adverse health outcomes in older adults, including overweight/obesity and increased waist circumference ${ }^{2}$. However, few studies have examined associations of sedentary behavior with overweight/obesity in older adults in developing countries ${ }^{3}$.
Obesity is a major risk factor for non-communicable diseases and has reached epidemic proportions worldwide, with more than one billion adults classified as overweight and at least 300 million as obese ${ }^{4}$. These numbers have led the World Health Organization (WHO) to declare obesity as a major public health concern ${ }^{5}$.

In epidemiological studies with older adults, body mass index (BMI) is an important anthropometric measure for classifying individuals as overweight or 
obese $^{6}$, and has been characterized as a risk factor for several morbidities ${ }^{7}$. One factor that may explain the relationship of sedentary behavior with cardiovascular risk factors is abdominal adiposity, measured by waist circumference, which is prospectively associated with an increased risk of mortality and cardiometabolic risk ${ }^{8}$.

Older adults usually engage in daily habits that demand lower energy expenditure when compared to other age groups. These habits include sedentary behaviors with high prevalence of activities such as watching television. It is currently recommended that all seniors should engage in physical activity and avoid sedentary lifestyle ${ }^{9}$. In this sense, the objective of this study was to analyze the association of sedentary behavior with overweight and abdominal obesity in Brazilian older adults.

\section{Methods}

This is a cross-sectional, population-based study, part of a larger study entitled "Health profile of the elderly population of the municipalities of the Regional Healthcare Administration - Uberaba, Minas Gerais", with older adults ( $\geq 60$ years) of both sexes and residents of the 24 towns belonging to the Regional Health Superintendency of Uberaba, Minas Gerais, conducted from May 2012 to April 2013.

The study sample was based on a population of 79.924 people aged $\geq 60$ years $^{10}$. Sample size was calculated based on the elderly population of each city ${ }^{10}$ as well as the following parameters: a sampling error of 5\%; a $95 \%$ confidence interval; and the number of elderly persons as a percentage of the total population of each city. These calculations indicated that a sample size of at least 3,198 individuals was necessary. Through the municipal Health Department and Family Health Strategy all individuals aged 60 or older living in the urban regions were invited to attend the Primary Health Care Units of the municipalities to participate in the health assessment.

The following inclusion criteria were adopted: participants were required to achieve the minimum score in the Mini-Mental State Examination according to the education level ${ }^{11}$ and to be able to walk even with the aid of a walking cane or walker.

Data collection was conducted by trained interviewers. All participants were informed about the study objectives and protocol, and provided written informed consent. The study protocol was previously approved by the Human Research Ethics Committee of the Federal University of Triangulo Mineiro (1640/2010).
Participants answered a structured questionnaire containing questions on demographic characteristics, perceived health, and health-related behaviors. Participants body mass $(\mathrm{kg})$, height (meters) and waist circumference $(\mathrm{cm})$ were measured using a weight scale, a stadiometer, and a measuring tape.

The sociodemographic characteristics assessed in the current study were sex (male, female), schooling (schooled and unschooled), marital status (living with a partner, not living with partner), retirement status (yes, no), monthly household income $(<\$ 228.39 ; \geq \$$ $228.39 \leq \$ 685.17$ e $>\$ 685.17)$, and age $(60-64,65-$ $69,70-74,75-79, \geq 80$ years).

The health-related variables evaluated in this study were perceived health, and functional status. Perceived health was evaluated considering the last 12 months. Participants were asked to rate their health as excellent, good, fair or poor. Responses were later recategorized into two levels: negative perception (bad or poor) and positive perception (excellent or good). In the current study, the Independence in Activities of Daily Living Index (Katz Index) adapted for Brazi ${ }^{12}$ was used to evaluate functional status of the older adults. Functional disability was identified by the presence of restrictions in independently performing basic activities of daily living and was analyzed dichotomously: independent (difficulty in any of the activities) versus dependent (difficulty/ inability to perform one or more activities). Health-related behaviors assessed in this study were smoking (yes, no), alcohol consumption (yes, no) and regular physical activity. Regular physical activity was assessed with question: Do you engage in physical activity regularly? Answer to this question was either yes or no.

Sedentary behavior was evaluated using time spent sitting according to the questions from the International Physical Activity Questionnaire (IPAQ) ${ }^{13}$. The two IPAQ questions on sedentary behavior are: 1) How long, in total, do you spend sitting on a weekday?; 2) How long, in total, do you spend sitting on a weekend day? The answer is given in hours and minutes. Total sedentary behavior for a regular week was estimated according the weighted average: time on weekdays times five plus time at the weekend day times two. This result was divided by seven.

Based on total time spent in sedentary behavior ( $\mathrm{min} /$ day), participants were divided in groups according to quartiles of distribution. Sedentary behavior values for the $1 \mathrm{st}, 2 \mathrm{nd}, 3 \mathrm{rd}$, and 4th quartiles were = 137.14 , $>137.14$ and $=240.00,>240.00$ and $=330.00$, and $>330.00 \mathrm{~min} /$ day, respectively. 
BMI was calculated by dividing body weight in kilograms by height in meters squared $\left(\mathrm{kg} / \mathrm{m}^{2}\right)$. Based on the BMI, older adults were classified according to the recommendation of the WHO: BMI $<18.5 \mathrm{~kg} /$ $\mathrm{m}^{2}$ (underweight); BMI 18.5-24.9 $\mathrm{kg} / \mathrm{m}^{2}$ (normal weight); BMI $25.0-29.9 \mathrm{~kg} / \mathrm{m}^{2}$ (overweight) and BMI $\geq 30 \mathrm{~kg} / \mathrm{m}^{2}$ (obesity) ${ }^{4}$.

Waist circumference was measured at the midpoint between the iliac crest and the last rib ${ }^{14}$.Values: $\geq 80$ $\mathrm{cm}$ and $\geq 94(\mathrm{~cm})$ are defined as abdominal obesity for women and men, respectively, according to the $\mathrm{WHO}^{15}$.

BMI was categorized dichotomously [normal weight corresponds to the absence of the outcome; and overweight $\left(\mathrm{BMI} \geq 25.00 \mathrm{~kg} / \mathrm{m}^{2}\right)$ corresponds to the presence of outcome]. Underweight participant ( $\mathrm{n}=$ 100) were excluded from the regression analysis.

Data were double entered, using Excel, version 2007. Statistical analyses were conducted with SPSS (Statistical Package for Social Sciences, version 20.0). Statistical significance was set at $\mathrm{p}<0.05$. Distributions were calculated as absolute and relative frequencies for the different variables. Quantitative variables were described by the mean and standard deviation (sd) or median and $25^{\text {th }}, 75^{\text {th }}$ percentile. Comparisons between quartiles of sedentary behavior and sociodemographic, perceived health, and health-related behavior variables were evaluated by chi-square statistical tests.

Poisson regression (prevalence ratios - PR, and 95\% confidence intervals $-95 \% \mathrm{CI}$ ) analyses with robust variance were used to examine the associations between quartiles of sedentary time with overweight and abdominal obesity, following three stages: 1) Crude Poison regression were conducted for examining associations of sociodemographic variables, perceived health, and health-related behaviors with the dependent variables: overweight and abdominal obesity. Variables presenting associations at the significance level of $\mathrm{p}<0.20$ were selected for adjustment; 2) Crude Poison regression was performed between quartiles of sedentary time with overweight and abdominal obesity; 3) Adjusted Poison regression was performed between quartiles of sedentary time with overweight and abdominal obesity, adjusted for the variables that presented $p<0.20$ in the first stage.

\section{Results}

A total of 3,430 older adults participated in the study. However, only 3,223 (93.9\%) had complete data for all variables. Mean age of participants was 70 years ( $\mathrm{sd}=$ $7.26)$, and the median $\left(25^{\text {th }}, 75^{\text {th }}\right.$ percentile) for seden- tary behavior was $240.00(137.14,330.00) \mathrm{min} /$ day.

When sociodemographic variables were analyzed according to quartiles of sedentary behavior, differences $(p<0.05)$ were observed between sex, age, schooling and monthly household (Table 1). For perceived health and health-related behavior, differences $(p<0.05)$ were observed for perceived health, basic activities of daily living, body mass index, waist circumference, and regular physical activity (Table 2).

In the analysis of quartiles of sedentary behavior with overweight, there were no significant associations both in crude and in adjusted analysis (Table 3). Regarding abdominal obesity, it was observed that participants from the $2^{\text {nd }}$ quartile of sedentary behavior more likely to present with abdominal obesity $(\mathrm{PR}=$ 1.06; 95\%CI: 1.01-1.12) when compared to the referent group, in the crude analyzis. However, when the adjusted analysis was performed, no significant associations were observed (Table 4).

\section{Discussion}

This study examined the associations of sedentary behavior with overweight and abdominal obesity. The results showed that older people exposed to long periods of sedentary behavior did not present with overweight status and abdominal obesity in the current study.

The absence of associations of sedentary behavior and physical activity with obesity and abdominal obesity is in agreement with the meta-analysis by Camilo et $\mathrm{al}^{3}$. The authors identified four studies examining the association association between sedentary behavior and overweight. These studies did not demonstrate an increased chance of overweight in those older adults with longer exposure to sedentary behavior. In addition, the authors emphasized that the great heterogeneity of the meta-analysis was due to variability in the sedentary behavior markers and their respective cut-off points.

By examining sedentary behavior according to sociodemographic variables, we observed that sedentary behavior decreased among older adults with schooling, which corroborates the study of Mielke et al. ${ }^{16}$. Also, monthly household income can contribute to high sedentary behavior. This association was observed in a previous study that showed that watching television is still the dominant sedentary behavior among brazilians with lower income ${ }^{17}$.

In this study, older adults who were dependent in basic activities of daily living had higher frequency of exposure to sedentary behavior, compared to older adults who were independent. There is evidence that prolonged 
Table 1 - Distribution of sociodemographic variables of the older adults according to quartiles of sedentary behavior. Regional Health Superintendence of Uberaba, Minas Gerais, 2012/2013 ( $n=3,223$ ).

\begin{tabular}{|c|c|c|c|c|c|c|}
\hline \multirow[t]{2}{*}{ Variables } & $\begin{array}{c}\text { Total } \\
(\mathrm{n}=3223)\end{array}$ & $\begin{array}{c}1^{\text {st }} \text { Quartile } \\
(\mathrm{n}=822)\end{array}$ & $\begin{array}{c}2^{\text {nd }} \text { Quartile } \\
(\mathrm{n}=1059)\end{array}$ & $\begin{array}{c}3^{\text {rd }} \text { Quartile } \\
(\mathrm{n}=545)\end{array}$ & $\begin{array}{c}4^{\text {th }} \text { Quartile } \\
(\mathrm{n}=797)\end{array}$ & \multirow[t]{2}{*}{$\mathrm{p}$-value } \\
\hline & $\mathrm{n}(\%)$ & $\mathrm{n}(\%)$ & $\mathrm{n}(\%)$ & $\mathrm{n}(\%)$ & $\mathrm{n}(\%)$ & \\
\hline \multicolumn{7}{|l|}{ Sex } \\
\hline Male & $1246(38.7)$ & $294(23.6)$ & $420(33.7)$ & $195(15.7)$ & $337(27.0)$ & \multirow[t]{2}{*}{0.022} \\
\hline Female & $1977(61.3)$ & $528(26.7)$ & $639(32.3)$ & $350(17.7)$ & $460(23.3)$ & \\
\hline \multicolumn{7}{|l|}{ Age } \\
\hline $60-64$ years & $884(27.4)$ & $239(27.0)$ & $294(33.3)$ & $149(16.9)$ & $202(22.9)$ & \multirow[t]{5}{*}{$<0.001$} \\
\hline $65-69$ years & $813(25.2)$ & $199(24.5)$ & $297(36.5)$ & $147(18.1)$ & $170(20.9)$ & \\
\hline $70-74$ years & $688(21.3)$ & $176(25.6)$ & $237(34.4)$ & $102(14.8)$ & $173(25.1)$ & \\
\hline $75-79$ years & $460(14.3)$ & $108(23.5)$ & $130(28.3)$ & $95(20.7)$ & $127(27.6)$ & \\
\hline$\geq 80$ years & $378(11.7)$ & $100(26.5)$ & $101(26.7)$ & $52(13.8)$ & $125(33.1)$ & \\
\hline \multicolumn{7}{|l|}{ Schooling } \\
\hline Schooled & $2288(71.0)$ & $579(25.3)$ & $790(34.5)$ & $382(16.7)$ & $537(23.5)$ & \multirow[t]{2}{*}{0.007} \\
\hline Unschooled & $935(29.0)$ & $243(26.0)$ & $269(28.8)$ & $163(17.4)$ & $260(27.8)$ & \\
\hline \multicolumn{7}{|l|}{ Marital status } \\
\hline Living with partner & $1829(56.7)$ & $466(25.5)$ & $611(33.4)$ & $315(17.2)$ & $437(23.9)$ & \multirow[t]{2}{*}{0.609} \\
\hline Not living with partner & 1394 (43.3) & $356(25.5)$ & $448(32.1)$ & $230(16.5)$ & $360(25.8)$ & \\
\hline \multicolumn{7}{|l|}{ Retired } \\
\hline Yes & $2594(80.5)$ & $645(24.9)$ & $855(33.0)$ & $446(17.2)$ & $648(25.0)$ & \multirow[t]{2}{*}{0.370} \\
\hline No & $629(19.5)$ & $177(28.1)$ & $204(32.4)$ & $99(15.7)$ & $149(23.7)$ & \\
\hline \multicolumn{7}{|l|}{ Monthly household income } \\
\hline$<\$ 228.39$ & $546(16.9)$ & $166(30.4)$ & $163(29.9)$ & $76(13.9)$ & $141(25.8)$ & \multirow[t]{3}{*}{0.011} \\
\hline$\geq \$ 228.39 \leq \$ 685.17$ & $2291(71.1)$ & $578(25.2)$ & $759(33.1)$ & $401(17.5)$ & $553(24.1)$ & \\
\hline$>\$ 685.17$ & $386(12.0)$ & $78(20.2)$ & $137(35.5)$ & 68 (17.6) & $103(26.7)$ & \\
\hline
\end{tabular}

Chi-Square -1 st Quartile $=$ Sitting time $\leq 137.14 ;$ 2nd Quartile $=$ Sitting time $>137.15$ to $\leq 240.00$; 3rd Quartile $=$ Sitting time $>240.1$ to $\leq$ 330.00; 4 th Quartile $=$ Sitting time $>330.00$ minutes/day.

periods of sitting are associated with disability in activities of daily living in older adults ${ }^{18}$. The current study also demonstrated that negative perceptions of health increased significantly from the lower to the upper quartile of sedentary behavior. Data from a recent study found that older adults who watch more television are more likely to report negative perceptions of health ${ }^{19}$. There is evidence that adults with more frequent interruptions of sedentary behavior over time, regardless of the total time/day in sedentary behavior and physical activity, had better measures of waist circumference ${ }^{20}$. In other words, we believe that eutrophic individuals with fewer disabilities are more disruptive to sedentary behavior when compared to obese individuals. Shuval et al. ${ }^{21}$ using the same methods from our study (self-reported sedentary behavior categorized into quartiles) found that individuals in the 4th quartile of sedentary behavior $(>6.5 \mathrm{~h} /$ day) were twice as likely (OR $=2.04$; 95\%CI: $1.19-3.5)$ to present with overweight status $\left(\mathrm{BMI} \geq 25 \mathrm{kgm}^{2}\right.$ ) when compared to the referent quartile, even after adjusting for sex, age, marital status, physical activity, transportation, ethnicity and health status. The authors highlighted that time spent sitting in passive leisure activities, such as computer use and time in motor vehicles, are risk factors for obesity in the population.

In order to explore joint associations of television viewing time and moderate to vigorous physical activities with overweight status, Inoue et al. ${ }^{22}$ conducted a study with 1806 japanese older adults. The authors found that watching television for long periods/week (> $840 \mathrm{~min} /$ week) was associated with excess weight. The study by Gennuso et al..$^{23}$ also found similar results, identifying strong and independent positive associations between sedentary behavior, body mass index and waist circumference; even when adjusted for sex, income, marital status, alcohol consumption, smoking, cardiovascular disease, body mass index and accelerometer wear time.

In our study, the univariate regression showed that older adults with sedentary behavior ranging from > 137.14 to $\leq 240 \mathrm{~min} /$ day were more likely to present with abdominal obesity in comparison to those older adults who spent less than $137.14 \mathrm{~min} /$ day sitting. 
Table 2 - Distribution of health-related behavior according to quartiles of sedentary behavior. Regional Health Superintendence of Uberaba, Minas Gerais, 2012/2013 ( $\mathrm{n}=3,223$ ).

\begin{tabular}{|c|c|c|c|c|c|c|}
\hline \multirow[t]{2}{*}{ Variables } & $\begin{array}{c}\text { Total } \\
(\mathrm{n}=3223)\end{array}$ & $\begin{array}{c}1^{\text {st }} \text { Quartile } \\
(\mathrm{n}=822)\end{array}$ & $\begin{array}{c}2^{\text {nd }} \text { Quartile } \\
(\mathrm{n}=1059)\end{array}$ & $\begin{array}{c}3^{\text {rd }} \text { Quartile } \\
(\mathrm{n}=545)\end{array}$ & $\begin{array}{c}4^{\text {th }} \text { Quartile } \\
(\mathrm{n}=797)\end{array}$ & \multirow[t]{2}{*}{$\mathrm{p}$-value } \\
\hline & $\mathrm{n}(\%)$ & $\mathrm{n}(\%)$ & $\mathrm{n}(\%)$ & $\mathrm{n}(\%)$ & $\mathrm{n}(\%)$ & \\
\hline \multicolumn{7}{|l|}{ Perceived health } \\
\hline Negative & $1677(52.0)$ & $441(26.3)$ & $496(29.6)$ & $288(17.2)$ & $452(27.0)$ & \multirow[t]{2}{*}{$<0.001$} \\
\hline Positive & $1546(48.0)$ & $381(24.6)$ & $563(36.4)$ & $257(16.6)$ & $345(22.3)$ & \\
\hline \multicolumn{7}{|c|}{ Basic activities of daily living } \\
\hline Independent & $2750(85.3)$ & $715(26.0)$ & $938(34.1)$ & $464(16.9)$ & $633(23.0)$ & \multirow[t]{2}{*}{$<0.001$} \\
\hline Dependent & $473(14.7)$ & $107(22.6)$ & $121(25.6)$ & 81 (17.1) & $164(34.7)$ & \\
\hline \multicolumn{7}{|l|}{ Body mass index } \\
\hline Underweight & $100(3.1)$ & $32(19.0)$ & $19(19.0)$ & $15(15.0)$ & $34(34.0)$ & \multirow[t]{4}{*}{0.004} \\
\hline Normal weight & $1090(33.8)$ & $292(26.8)$ & $362(33.2)$ & $183(16.8)$ & $253(23.2)$ & \\
\hline Overweight & $1218(37.8)$ & $323(26.5)$ & $410(33.7)$ & $204(16.7)$ & $281(23.1)$ & \\
\hline Obesity & $815(25.3)$ & $175(21.5)$ & $268(32.9)$ & $143(17.5)$ & $229(28.1)$ & \\
\hline \multicolumn{7}{|l|}{ Waist circumference } \\
\hline Normal & $784(24.3)$ & $215(27.4)$ & $229(29.4)$ & $121(15.4)$ & $219(27.9)$ & \multirow[t]{2}{*}{0.010} \\
\hline Abdominal obesity & $2439(75.7)$ & $607(24.9)$ & $830(34.0)$ & $424(17.4)$ & $578(23.7)$ & \\
\hline \multicolumn{7}{|l|}{ Smoking } \\
\hline Yes & $488(15.1)$ & $128(26.2)$ & $155(31.8)$ & $77(15.8)$ & $128(26.2)$ & \multirow[t]{2}{*}{0.732} \\
\hline No & $2735(84.9)$ & $694(25.4)$ & $904(33.1)$ & $468(17.1)$ & $669(24.5)$ & \\
\hline \multicolumn{7}{|l|}{ Alcohol consumption } \\
\hline Yes & $510(15.8)$ & $111(21.8)$ & $187(36.7)$ & $85(16.7)$ & $127(24.9)$ & \multirow[t]{2}{*}{0.110} \\
\hline No & $2713(84.2)$ & $711(26.2)$ & $872(32.1)$ & $460(17.0)$ & $670(24.7)$ & \\
\hline \multicolumn{7}{|c|}{ Regular physical activity } \\
\hline Yes & $1839(57.1)$ & $491(26.7)$ & $628(34.1)$ & $336(18.3)$ & $384(20.9)$ & \multirow[t]{2}{*}{$<0.001$} \\
\hline No & 1384 (42.9) & $331(23.9)$ & 431 (31.1) & 209 (15.1) & $413(29.8)$ & \\
\hline
\end{tabular}

Chi-Square -1 st Quartile $=$ Sitting time $\leq 137.14 ;$ 2nd Quartile $=$ Sitting time $>137.15$ to $\leq 240.00$; 3rd Quartile $=$ Sitting time $>240.1$ to $\leq$ 330.00; 4th Quartile $=$ Sitting time $>330.00$ minutes/day.

Table 3 - Association of sedentary behavior with overweight. Regional Health Superintendence of Uberaba, Minas Gerais, 2012/2013 ( $\mathrm{n}=3$,223).

\begin{tabular}{|c|c|c|c|c|}
\hline \multirow[b]{2}{*}{ Sedentary behavior (min/d) } & \multicolumn{4}{|c|}{ Overweight } \\
\hline & $\begin{array}{l}\text { Crude analysis } \\
\text { PR (95\%CI) }\end{array}$ & $\mathrm{p}$-value & $\begin{array}{c}\text { Adjusted analysis } \\
\text { PR }(95 \% \mathrm{CI})^{*}\end{array}$ & p-value* \\
\hline $1^{\text {st }}$ Quartile $(0 \leq 137.14)$ & 1.00 & & 1.00 & \\
\hline $2^{\text {nd }}$ Quartile (> $\left.137.14 \leq 240.00\right)$ & $1.03(0.97-1.11)$ & 0.343 & $0.99(0.94-1.05)$ & 0.752 \\
\hline $3^{\text {rd }}$ Quartile (> $\left.240 \leq 330.00\right)$ & $1.04(0.96-1.13)$ & 0.363 & $0.99(0.93-1.07)$ & 0.915 \\
\hline $4^{\text {th }}$ Quartile $(>330.00)$ & $1.06(0.99-1.14)$ & 0.116 & $1.07(1.00-1.13)$ & 0.047 \\
\hline
\end{tabular}

*Adjusted for sex, age, schooling, monthly household income, regular physical activity, basic activities of daily living, perceived health, and waist circumference.

Table 4 - Association of sedentary behavior with abdominal obesity. Regional Health Superintendence of Uberaba, Minas Gerais, 2012/2013 $(\mathrm{n}=3,223)$.

\begin{tabular}{|c|c|c|c|c|}
\hline \multirow[b]{2}{*}{ Sedentary behavior $(\mathrm{min} / \mathrm{d})$} & \multicolumn{4}{|c|}{ Abdominal obesity } \\
\hline & $\begin{array}{l}\text { Crude analysis } \\
\text { PR (95\% CI) }\end{array}$ & $\mathrm{p}$-value & $\begin{array}{l}\text { Adjusted analysis } \\
\text { PR (95\% CI)* }\end{array}$ & p-value* \\
\hline $1^{\text {st }}$ Quartile $(0 \leq 137.14)$ & 1.00 & & 1.00 & \\
\hline $2^{\text {nd }}$ Quartile (> $\left.137.14 \leq 240.00\right)$ & $1.06(1.01-1.12)$ & $0.024^{*}$ & $1.04(1.00-1.08)$ & 0.064 \\
\hline $3^{\text {rd }}$ Quartile $(>240 \leq 330.00)$ & $1.05(0.99-1.12)$ & 0.091 & $1.03(0.98-1.08)$ & 0.202 \\
\hline $4^{\text {th }}$ Quartile (> 330.00) & $0.98(0.93-1.04)$ & 0.548 & $0.98(0.94-1.03)$ & 0.538 \\
\hline
\end{tabular}

*Adjusted for sex, age, schooling, monthly household income, regular physical activity, basic activities of daily living, perceived health, and body mass index. 
However, after adjusting for covariates, the association did not hold significance. This result is similar to that observed by Shuval et al. ${ }^{21}$. The lack of statistical significance may be partly due to sample homogeneity, as $75.7 \%$ of the older adults were classified with abdominal obesity. However, in a cross-sectional study of 466,605 Chinese adults and older adults of both sexes, sedentary behavior was associated with larger waist circumference, after adjustment - for confounding factors ${ }^{24}$.

Although our study does not allow for determining causality, longitudinal studies have shown a cause and effect relationship between sedentary behavior and waist circumference. For example, over a period of five years, the increase in television viewing time was followed by significant adverse changes in waist circumference in Australian adults of both sexes ${ }^{25}$.In another cohort an increase of 2 hours of television viewing per day resulted in a $\mathrm{OR}=1.28(95 \% \mathrm{CI}: 1.21-1.36)$ for the risk of obesity $^{19}$. In the study by Saunders et al. ${ }^{8}$, each increase of 15 minutes in sedentary behavior exposures after six years of follow-up was associated with an increase of $0.13 \mathrm{~cm}$ in waist circumference of adults aged 18-65 years. This result was significant even after adjustment for age, sex, body mass index, smoking, physical activity level, caloric expenditure, schooling, and income.

In addition to associations of sedentary behavior with morbidities, it is important to highlight that high exposure to sedentary behavior, is positively associated with mortality ${ }^{26}$. The literature also provides results consistent with the hypothesis that the replacement of sedentary activities with low-intensity activities can lead to lower levels of BMI and obesity prevalence in older adults from the general population. The study by Bann et al. ${ }^{27}$ showed that more time spent in low intensity activities concomitantly with less time in sedentary behavior was associated with lower BMI in American older adults; whereas time spent watching TV was positively associated with BMI.

Pulsford et al. ${ }^{28}$ conducted a study to examine cross-sectional and prospective associations between sedentary behavior and obesity indicators $\left(B M I \geq 30 \mathrm{~kg} / \mathrm{m}^{2}\right)$. The authors also examined the possibility of reverse causality. The results, showed that obesity, measured by BMI, at the beginning of the study was prospectively associated with increased time watching television in older adults. The impact of sedentary behavior and physical activity on excessive weight varies with age and can be a major risk factor for older adults, because the latter usually become less active and spend more time in sedentary behavior over time ${ }^{22}$. Data from the Family Budget Survey of Bra- zil (POF 2008-2009) indicated that, while the prevalence of overweight increased with age, in age groups older than 75 years there was a systematic decrease in body weight. Conversely, underweight status was higher in individuals over 75 years, compared to other age groups ${ }^{29}$.

The present study shows some points that might be considered worthy of attention. Firstly, we highlight the inclusion of a high number of older adults, which consisted of a representative sample of the population examined. In addition, all participants were first screened with the Mini-Mental State Examination according to schooling, minimizing the interference of education level on the quality of self-reported information obtained with the questionnaire. As limitations, it is important to cite the use of a self-report instrument to assess sedentary behavior. Self-report measures are dependent on participants memory and recall ability, which are more frequently compromised in older adults. In addition, self-report measures of sedentary behavior usually lead to underestimation of results. However, these types of instruments are still commonly used in large-scale studies. In a systematic review of longitudinal studies conducted from 1996 and 2011, 46 of the 48 articles that met inclusion criteria used self-reported measures, which include total time watching television as well as other screen behaviors $^{30}$. Thus, we believe that more studies using objective measures of sedentary behavior are necessary. Finally, the cross-sectional design of the study does not permit to establish a cause-effect relationship.

In summary, the current study demonstrated that sedentary behavior was not associated with overweight and abdominal obesity. Our finding highlights the need for new studies examining if there is a causal relationship between sedentary behavior and overweight/obesity and to determine the factors that may mediate this association.

\section{Conflict of interest.}

The authors declare no conflict of interest.

\section{Author's contributions}

Resende TIM, contributed to the writing of the work, data collection and statistical analysis, and interpretation of the data for the article. Meneguci J, contributed to data collection and correction of the article. Sasaki JE, contributed to the writing of the work and critical review of its intellectual content. Santos AS, contributed to the conception of the study and critical review of its intellectual content. Damião $\mathrm{R}$, contributed to the conception of the study and critical review of its intellectual content. All authors have approved the final version of the manuscript to be published. 


\section{References}

1. Matthews CE, Chen KY, Freedson PS, Buchowski MS, Beech BM, Pate RR, et al. Amount of time spent in sedentary behaviors in the United States, 2003-2004. Am J Epidemiol. 2008;167:875-81.

2. Rezende LF, Rey-López JP, Matsudo VK, Carmo Luiz O. Sedentary behavior and health outcomes among older adults: a systematic review. BMC Public Health. 2014;14:333.

3. Camilo BF, Resende TIM, Moreira ÉFA, Damião R. Sedentary behavior and nutritional status among older adults: a meta-analysis. Rev Bras Med Esporte. 2018;24(4):310-15.

4. World Health Organization. Global strategy on Diet, Physical Activity and Health Obesity and Overweight. March, 2011.

5. World Health Organization. Obesity: Preventing and Managing the Global Epidemic. Report of a WHO Consultation on Obesity, Geneva, 1998.

6. Nascimento CM, Ribeiro AQ, Cotta RMM, Acurcio FA, Peixoto SV, Priore SE, et al. Estado nutricional e fatores associados em idosos do Município de Viçosa, Minas Gerais, Brasil. Cad. Saúde Pública. 2011;27:2409-18.

7. Bassler TC, Lei DLM. Diagnóstico e Monitoramento da Situação Nutricional da população idosa no município $\mathrm{da}$ região metropolitana de Curitiba (PR). Rev Nutr. 2008;21:311-21.

8. Saunders TJ, Tremblay MS, Després JP, Bouchard C, Tremblay A, Chaput JP. Sedentary Behaviour, Visceral Fat accumulation and Cardiomatabolic risk in adults: A 6- Year longitudinal Sutdy from the Quebec Family study. PLoS One. 2013;8:54225.

9. Chodzko-zajko WJ, Proctor DN, Fiatarone Singh MA, Minson CT, Nigg CR, Salem GJ, et al. Exercise and Physical Activity for Older Adults; by the American College of Sports Medicine. Med Sci Sports Exerc. 2009;41:1510-30.

10. IBGE. Instituto Brasileiro de Geografia e Estatística. 2011. [cited 2013 Aug 03]. Available from: http://www.ibge. gov.br/home/estatistica/populacao/censo2010/resultados_ preliminares/preliminar_tab_municipio_zip.shtm

11. Bertolucci PHF, Brucki SMD, Campacci SR, Juliano Y. O Mini-Exame do Estado Mental em uma população geral: impacto da escolaridade. Arq Neuropsiquiatr. 1994;52:1-7.

12. Lino VTS, Pereira SRM, Camacho LAB, Ribeiro Filho ST, Buksman S. Adaptação transcultural da Escala de Independência em Atividades da Vida Diária (Escala de Katz). Cad Saúde Pública. 2008;24:103-12.

13. Rosenberg DE, Bull FC, Marshall AL, Sallis JF, Bauman AE. Assessment of sedentary behavior with the International Physical Activity Questionnaire. J Phys Act Health. 2008;1:30-44.

14. World Health Organization. Diet, nutrition and the prevention of chronic diseases. Geneva: World Health Organization, 2002.

15. World Health Organization. Waist circumference and waisthip ratio: report of a WHO expert consultation. Geneva, 2008.

16. Mielke GI, Hallal PC, Malta DC, Lee IM. Time trends of physical activity and television viewing time in Brazil: 20062012. Int J Behav Nutr Phys Act. 2014;11:101.

17. Mielke GI, Silva IC, Owen N, Hallal PC. Brazilian adults' sedentary behaviors by life domain: population-based study. PloS One. 2014;9:e91614.
18. Virtuoso Júnior JS, Tribess S, Rocha SV, Sasaki JE, Garcia CA, Meneguci J, et al. Sedentary behavior as a predictor of functional disability in older adults. Rev Bras Ati Fis Saúde. 2018;23:e010.

19. Hamer M, Weiler R, Stamatakis E. Watching sport on television, physical activity, and risk of obesity in older adults. BMC Public Health. 2014;14:10.

20. Healy GN, Dunstan DW, Salmon J, Cerin E, Shaw JE, Zimmet PZ, Owen N. Breaks in sedentary time: beneficial associations with metabolic risk. Diabetes Car.2008;31:661-6.

21. Shuval K, Leonard T, Murdoch J, Caughy MO, Kohl HW 3rd, Skinner CS. Sedentary Behaviors and Obesity in a LowIncome, Ethnic-Minority population. J Phys Act Health. 2013;10:132-6.

22. Inoue $S$, Sugiyama $T$, Takamiya $T$, Oka K, Owen $N$, Shimomitsu T. Television Viewing Time is Associated with Overweight/Obesity Among Older Adults, Independent of Meeting Physical Activity and Health Guidelines. J Epidemiol. 2012;22:50-6.

23. Gennuso KP, Gangnon RE, Matthews CE, ThraenBorowski KM, Colbert LH. Sedentary Behavior, Physical Activity, and Markers of Health in Older Adults. Med Sci Sports Exerc. 2013;45:1493-500.

24. Du H, Bennett D, Li L, Whitlock G, Guo Y, Collins R, et al. Physical activity and sedentary leisure time and their associations with BMI, waist circumference, and percentage body fat in 0.5 million adults: the China Kadoorie Biobank study. Am J Clin Nutr. 2013;97:87-96.

25. Wijndaele K, Healy GN, Dunstan DW, Barnett AG, Salmon J, Shaw JE, et al. Increased cardio-metabolic risk is associated with increased TV viewing time. Med Sci Sports Exerc. 2010;42:1511-8.

26. Diaz KM, Howard VJ, Hutto B, Colabianchi N, Vena JE, Safford MM, et al. Patterns of Sedentary Behavior and Mortality in U.S. Middle-Aged and Older Adults: A National Cohort Study. Ann Intern Med. 2017;167(7):465-75.

27. Bann D, Hire D, Manini T, Cooper R, Botoseneanu A, McDermott MM, et al. Light Intensity Physical Activity and Sedentary Behavior in Relation to Body Mass Index and Grip Strength in Older Adults: Cross-Sectional Findings from the Lifestyle Interventions and Independence for Elders (LIFE) Study. Plos One. 2015;10:1-13.

28. Pulsford RM, Stamatakis E, Britton AR, Brunner EJ, Hillsdon MM. Sitting behavior and obesity: evidence from the Whitehall II study. Am J Prev Med. 2013;44:132-8.

29. Brazilian Institute of Geography and Statistics. Consumer Expenditure Survey 2008-2009: Anthropometry and Nutritional Status of Children, Adolescents and Adults in Brazil. Rio de Janeiro; 2010. [cited 2017 Feb 22]. Available from: http:// https://biblioteca.ibge.gov.br/visualizacao/ livros/liv45419.pdf.

30. Thorp AA, Owen N, Neuhaus M, Dunstan DW. Sedentary behaviors and subsequent health outcomes in adults a systematic review of longitudinal studies, 1996-2011. Am J Prev Med. 2011;41:207-15.

Received: 22/04/2019 Approved: 13/08/2019 